\title{
Tandem fecal microbiota transplantation cycles in an allogeneic hematopoietic stem cell transplant recipient targeting carbapenem-resistant Enterobacteriaceae colonization: a case report and literature review
}

Fengqin Su ${ }^{1,2}, Y_{i} L_{u o}^{1,2}$, Jian Yu ${ }^{1,2}$, Jimin Shi ${ }^{1,2}$, Yanmin Zhao ${ }^{1,2}$, Mengni Yan ${ }^{1,2}$, He Huang ${ }^{1,2}$ and Yamin $\operatorname{Tan}^{1,3^{*}}$ (1)

\begin{abstract}
Background: Due to limited antibiotic options, carbapenem-resistant Enterobacteriaceae (CRE) infections are associated with high non-relapse mortality after allogeneic hematopoietic stem cell transplantation (allo-HSCT). Also, intestinal CRE colonization is a risk factor for subsequent CRE infection. Several clinical studies have reported successful fecal microbiota transplantation (FMT) for the gut decontamination of a variety of multidrug-resistant bacteria (MDRB), even in immunosuppressed patients. Similarly, other studies have also indicated that multiple FMTs may increase or lead to successful therapeutic outcomes.
\end{abstract}

Case presentation: We report CRE colonization in an allo-HSCT patient with recurrent CRE infections, and its successful eradication using tandem FMT cycles at 488 days after allo-HSCT. We also performed a comprehensive microbiota analysis. No acute or delayed adverse events (AEs) were observed. The patient remained clinically stable with CRE-negative stool culture at 26-month follow-up. Our analyses also showed some gut microbiota reconstruction. We also reviewed the current literature on decolonization strategies for CRE.

Conclusions: CRE colonization led to a high no-relapse mortality after allo-HSCT; however, well-established decolonization strategies are currently lacking. The successful decolonization of this patient suggests that multiple FMT cycles may be potential options for CRE decolonization.

Keywords: Carbapenem-resistant Enterobacteriaceae colonization, Fecal microbiota transplantation, Gut microbiota, Hematopoietic stem cell transplantation, Multidrug-resistant bacteria

*Correspondence: yamin0001@126.com

1 Bone Marrow Transplantation Center, The First Affiliated Hospital,

Zhejiang University School of Medicine, 79 Qingchun Road, Hangzhou 310003, China

Full list of author information is available at the end of the article

\section{Background}

Carbapenem-resistant Enterobacteriaceae (CRE) pose a significant threat to global health due to limited antibiotic options, especially for immunocompromised patients, such as solid organ and hematological transplant recipients. In a nationwide Italian retrospective survey, CRE infection cases were reported in $53.4 \%$ of hematopoietic stem cell transplant (HSCT) centers, involving $2 \%$ of allogeneic-HSCT (allo-HSCT) recipients, with $39.2 \%$ of

c) The Author(s) 2021. This article is licensed under a Creative Commons Attribution 4.0 International License, which permits use, sharing, adaptation, distribution and reproduction in any medium or format, as long as you give appropriate credit to the original author(s) and the source, provide a link to the Creative Commons licence, and indicate if changes were made. The images or other third party material in this article are included in the article's Creative Commons licence, unless indicated otherwise in a credit line to the material. If material is not included in the article's Creative Commons licence and your intended use is not permitted by statutory regulation or exceeds the permitted use, you will need to obtain permission directly from the copyright holder. To view a copy of this licence, visit http://creativeco mmons.org/licenses/by/4.0/. The Creative Commons Public Domain Dedication waiver (http://creativecommons.org/publicdomain/ zero/1.0/) applies to the data made available in this article, unless otherwise stated in a credit line to the data. 
allo-HSCT patients colonized by subsequent CRE infections [1]. For hematological patients, CRE colonization is a known risk factor for subsequent CRE infections [2, 3]. Previous research has shown that CRE infection-related fatality rates, ranging from 52.2 to $64.4 \%$, occur in hematologic malignancies $[4,5]$.

Fecal microbiota transplantation (FMT) is a novel therapeutic strategy and is recommended by several international guidelines as an effective treatment option for recurrent Clostridium difficile infection (CDI) [6-9]. FMT is also being explored as a potential therapy for other conditions, including inflammatory bowel disease $[10,11]$, irritable bowel syndrome[12, 13], graft-versushost disease (GVHD) [14-17], the decolonization of multidrug-resistant bacteria (MDRB) [18-20], and several ongoing clinical trials; NCT04711967 (prospective study of FMT for acute intestinal GVHD after allo-HSCT) and NCT03678493 (a study of FMT in patients with AML allo-HSCT in recipients). FMT efficacy for MDRB decolonization is believed to be secondary to the transfer of organisms that restore microbiome diversity and provide colonization resistance [21]. Previous studies have suggested that multiple FMTs may increase the chance of successful therapeutic outcomes [22-24]. Thus, we hypothesized that multiple FMTs may exert significant effects on CRE decolonization in a manner similar to CDI. Therefore, we used tandem FMT cycles to successfully eradicate gut CRE in an allo-HSCT recipient with recurrent CRE infections. We also analyzed the gut microbiota to provide structural insights on ongoing microbiome reconfiguration.

\section{Case presentation}

A 45-year-old man with acute myeloid leukemia (AMLM5b) was subject to human leukocyte antigen-haploidentical relative HSCT for persistent minimal residual disease (MRD) (Fig. 1a). Apart from AML, the patient did not have any potentially relevant pre-existing conditions or medical treatments that may have impacted on bacterial colonization, clearance, or drug tolerance. The conditioning regimen comprised busulfan $(0.8 \mathrm{mg} /$ $\mathrm{kg} / \mathrm{q} 6 \mathrm{~h})$, cyclophosphamide $(60 \mathrm{mg} / \mathrm{kg} / \mathrm{d})$, and semustine $\left(250 \mathrm{mg} / \mathrm{m}^{2} / \mathrm{d}\right)$. Cyclosporin A, methotrexate, and mycophenolate mofetil were used for GVHD prophylaxis, and levofloxacin and cefotaxime/sulbactam were given for antimicrobial prophylaxis. Prior to conditioning therapy, carbapenem-resistant Klebsiella pneumoniae (CRKp) colonization, which has a high level of resistance to most routine antibiotics except for tigecycline (Additional file 1: Figure S1), was identified during routine rectal screening, while no decolonization strategies were performed. Six days after allo-HSCT, the patient developed neutropenic fever and the organism that grew in the blood culture was identified as CRKp which with the same resistance pattern as the previous one. CRKp bacteremia was successfully controlled by tigecycline. Hematopoietic stem cells were engrafted on day +11 and the patient discharged on day +20 . During regular follow-up, the patient was in remission, but suffered chronic oral GVHD as it had not responded well to prednisone and tacrolimus. Thus, the patient remained in a very poor nutritional state, weighing approximately $45 \mathrm{~kg}$ (height $=168 \mathrm{~cm}$ ).

A second fever episode was accompanied by chills, cough, and expectoration on day +421 . On this occasion, lung computerized tomography (CT) suggested pulmonary infection, and sputum and stool cultures were both positive for CRKp. This confirmed previous susceptibility tests, although blood cultures were negative. Infection was controlled by administering an antibiotic therapeutic regimen, including tigecycline. However, sputum and stool cultures remained positive for CRKp, indicating persistent CRKp colonization. Based on the same resistance patterns, we speculated that they were the same strain. Moreover, a previous study indicated that most bacteremia cases originated from the gut $[25,26]$. Thus, FMT was planned to reduce the risk of infection and improve future quality of life.

\section{Methods}

Frozen microbiota stocks were generated by a non-profit stool bank (MedBiome, Xian, China). The unrelated donor was a 23-year-old male volunteer, who was carefully screened using our inclusion and exclusion criteria (Additional file 2: Table S1) [27]. Prior to donation, the donor provided informed written consent and was provided with a nutritious, balanced diet, without seafood, spices, and unclean food for 3 days. This donor contributed independently two fecal samples for this study.

Donor fecal microbiota was prepared by the stoolbank in a Good Manufacturing Practice (GMP)-level laboratory and workflow. Fresh feces were purified using a newly developed automatic purification system (GenFMTer, MedBiome, Xian, China), which ensured increased quality control when compared with manual sample preparation. The process also significantly reduced FMT-related adverse events (AEs) by removing undigested food residues, fungi, parasite eggs, and some small particles [28]. The precipitate was removed from the washed fecal suspension by centrifugation, followed by washing three times in sterile saline, and re-centrifugation. Thus, crudely purified fecal microbiota precipitate was obtained, and approximately $30-40 \mathrm{ml}$ precipitate was resuspended in $30 \%$ sterile glycerin, packaged in each of three plastic bottles, and stored at $-80^{\circ} \mathrm{C}$. Each time, the laboratory supplied the three frozen microbiota 
a

\begin{tabular}{|c|c|c|c|c|c|c|}
\hline $\begin{array}{l}\text { Age at time of } \\
\text { allo-HSCT,y }\end{array}$ & Sex & Hematologic disease & Comorbidities & $\begin{array}{l}\text { Donor gender, } \\
\text { relationship }\end{array}$ & $\begin{array}{l}\text { Stem cell } \\
\text { source }\end{array}$ & $\begin{array}{l}\text { Conditioning } \\
\text { regimen }\end{array}$ \\
\hline 45 & Male & AML-M5b & No & $\begin{array}{l}\text { Female; } \\
\text { Matched related }\end{array}$ & PBSC & Myeloablative \\
\hline $\begin{array}{l}\text { Time point of } \\
\text { engraftment(days } \\
\text { after allo-HSCT) }\end{array}$ & aGVHD & cGVHD & $\begin{array}{l}\text { Identified } \\
\text { MDRB }\end{array}$ & $\begin{array}{l}\text { Time point of } \\
\text { FMT(days after } \\
\text { allo-HSCT) }\end{array}$ & FMT donor & $\begin{array}{l}\text { Way of } \\
\text { administration }\end{array}$ \\
\hline+11 & No & Oral GVHD & CRKp & +488 & Unrelated & $\begin{array}{l}\text { Nasoduodenal } \\
\text { tube }\end{array}$ \\
\hline
\end{tabular}
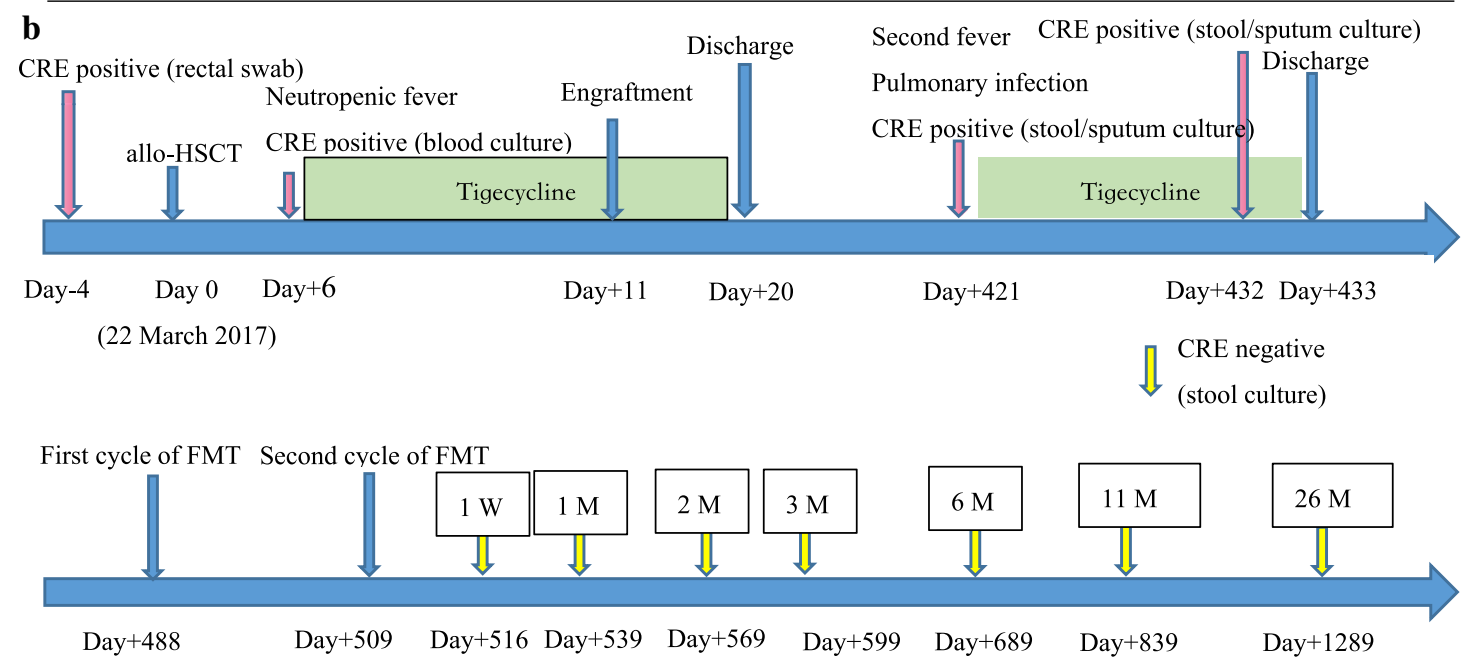

(23/25/27 July 2018) (13/15/17 August 2018)

Fig. 1 Characteristics of the patient. a Characteristics of the patient undergoing FMT before and after allo-HSCT. b The time line scale in days from the beginning of allo-HSCT allo-HSCT, allogeneic hematopoietic stem cell transplantation; AML acute myeloid leukemia, PBSC peripheral blood stem cells, GVHD graft-versus-host disease, CRKp carbapenem-resistant Klebsiella pneumonia, MDRB multidrug-resistant bacteria, FMT Fecal microbiota transplantation, CRE carbapenem-resistant Enterobacteriaceae, $W$ week, $M$ month

stocks for one cycle which were transported to the clinic on dry ice before the cycle.

Prior to FMT, the suspension from one plastic bottle was thawed at $37{ }^{\circ} \mathrm{C}$ and purified by repeated centrifugation. The precipitate was diluted to $200 \mathrm{ml}$ (except on one occasion when it was diluted to $250 \mathrm{ml}$ ) in sterile saline. It was then stirred, and was ready for use when completely homogenized.

Before the procedure, the patient provided written informed consent. To reduce the risk of failure, we performed tandem FMT cycles.

Fecal microbiota preparations were delivered to the intestine over 2-4 min using a nasoduodenal tube (localized using $\mathrm{X}$ rays). The patient then fasted for $2 \mathrm{~h}$ after which he was permitted to eat and drink normally. This procedure was repeated three times every other day for each course. Two courses were performed with a 17 day interval (23/25/27 July 2018 and 13/15/17 Aug 2018) (Fig. 1b). FMT was initiated at day +488 , while the patient was under prednisone immunosuppressive therapy, and no antibiotics were taken since his last discharge from hospital. The patient was observed for a few hours at the hospital after each procedure. He was regularly followed up in the outpatient clinic using stool culture samples.

For stool analysis, we performed the following; prior to FMT, 1 week and 3 weeks after the first cycle, and 1 week, 3 months, and 11 months after the second, we collected stool samples, extracted DNA, and analyzed 16 s rDNA amplicons using an Illumina Miseq (Genetalks, Changsha, China). Raw sequence data were analyzed using Quantitative Insights Into Microbial Ecology software (QIIME, version 1.9.1), and visualized by R (version 3.5.1, R Foundation for Statistical Computing, Vienna, Austria). 
Microbial diversity was estimated using the Shannon diversity index.

\section{Results}

The patient tolerated tandem FMT cycles without AEs during the initial process and follow-up period (26 months). Throughout follow-up after FMT termination, and for the next 26 months (between August 2018 and October 2020), stool cultures were CRE negative at 1 week, 1 month, 2 months, 3 months, 6 months, 11 months, and 26 months, and the patient remained clinically stable. The only fever episode occurred at 12 months, and included a positive sputum culture for the same CRKp as previously observed, but lung CT was clear and blood and stool cultures were negative. Empirical treatment with piperacillin/tazobactam did not control the fever, but it was quickly resolved by successive meropenem administration, suggesting that the CRKp may not have been the causative pathogen this time. A significant improvement was observed in oral chronic GVHD, and the patient gained approximately $5 \mathrm{~kg}$ over 8 months following FMT.

To identify correlations between fecal microbiota and clinical benefits, we evaluated changes in bacterial microbiota before and after FMT cycles using $16 \mathrm{~s}$ rDNA sequencing (Fig. 2). Prior to FMT, we detected pathobionts of the Proteobacteria phylum, more notably Escherichia/Shigella and Klebsiella, which accounted for $>33 \%$ of the whole community, and was far higher than healthy individuals [29]. Eleven months after tandem FMT cycles, with the expansion of the protective phylum, Bacteroidetes, the patients' microbial composition was eventually dominated by Firmicutes and Bacteroidetes, similar to normal commensal patterns (Fig. 2a) [30]. Bacteroidetes were associated with protection against Enterococcus domination [31], improved gut GVHD [32, 33], protection against CDI [34], and protection against Gram-negative blood infections [35], which were mainly associated with short-chain fatty acids' (SCFAs) production. In contrast, the outgrowth of opportunistic pathogens belonging to Proteobacteria had been linked to increased treatment-related mortality, including GVHD, infections, and organ failure after allo-HSCT [36]. In a recent study, recolonization with microbiota containing anaerobic Prevotella species as a keystone genus was correlated with CRE decolonization [37]. In our case, the donor's two fecal samples both contained significant Prevotella levels which are not ordinarily detected in patient's fecal microbiota before FMT. Also, levels were significant 3 weeks after the first FMT cycle and remained for 1 week after the second cycle (Fig. 2c). Although levels disappeared 3 weeks after the second FMT cycle, our observations suggest that Prevotella may play an important role in CRE decolonization. Fecal microbiota diversity (Shannon diversity index) also increased from 3.09 to 3.52 (final measurement) (Fig. 2b).

We also analyzed differences between the patient's fecal microbiota and the first or second donor fecal sample using UniFrac distance analysis (Fig. 3). The difference was dramatically increased after the second FMT cycle. This may have been due to the difference between the donor's two samples. The patient's fecal microbiota closely matched the donor's fecal microbiota after both cycles, suggesting that the grafted samples contributed to diversity recovery.

\section{Discussion and conclusions}

Previous reports have shown that colonization with MDRB, including CRE and vancomycin-resistant enterococci (VRE), exerts a negative impact on overall survival after allo-HSCT due to a higher incidence of infection, especially in patients with lower gut microbiota diversity [38]. Healthy gut microbiota can prevent invading pathogens from colonizing the intestinal tract, a phenomenon known as colonization resistance. This process is underpinned by several mechanisms, including competition for metabolic and physical niches, production of inhibitory metabolites, and interaction with the host immune system [39]. However, major factors including conditional chemotherapy and/or irradiation, antibiotic therapy, GVHD, mucositis, changes in diet, and infection (e.g., $C$. difficile) can alter microbiota homeostasis in allo-HSCT, and cause loss of this colonization resistance in alloHSCT recipients $[40,41]$. We therefore speculated that gut composition and diversity restoration by FMT could benefit allo-HSCT recipients and clear CRE from the gut.

The literature suggests that spontaneous CRE decolonization takes time. In a retrospective multicenter study conducted in two different tertiary care hospitals, the spontaneous decolonization of CRE and VRE occurred within the first 30 days in $16.4 \%$ of cases, and $48.2 \%$ after 3 months, with a median follow-up of 96 days (0-974) [42]. In addition, Haverkate et al. also reported that only $17 \%$ of long-term acute care hospital patients lost CRKp colonization within 4 weeks, and approximately $50 \%$ were still carriers after 9 months [43]. A previous meta-analysis reported that the rate of spontaneous CRE decolonization was only $23.3 \%$, and a significant proportion of carriers (35.2\%) were still colonized up to 12 months later [44].

The most common strategy for gut CRE decolonization is oral, non-absorbable antibiotics, including gentamicin, colistin, or polymyxin E, which must achieve sufficiently high concentrations in the digestive tract to inhibit bacterial growth. The decolonization rate of these antibiotics ranges between 37.5 and $71 \%$ [45-47], and up to $66 \%$ 


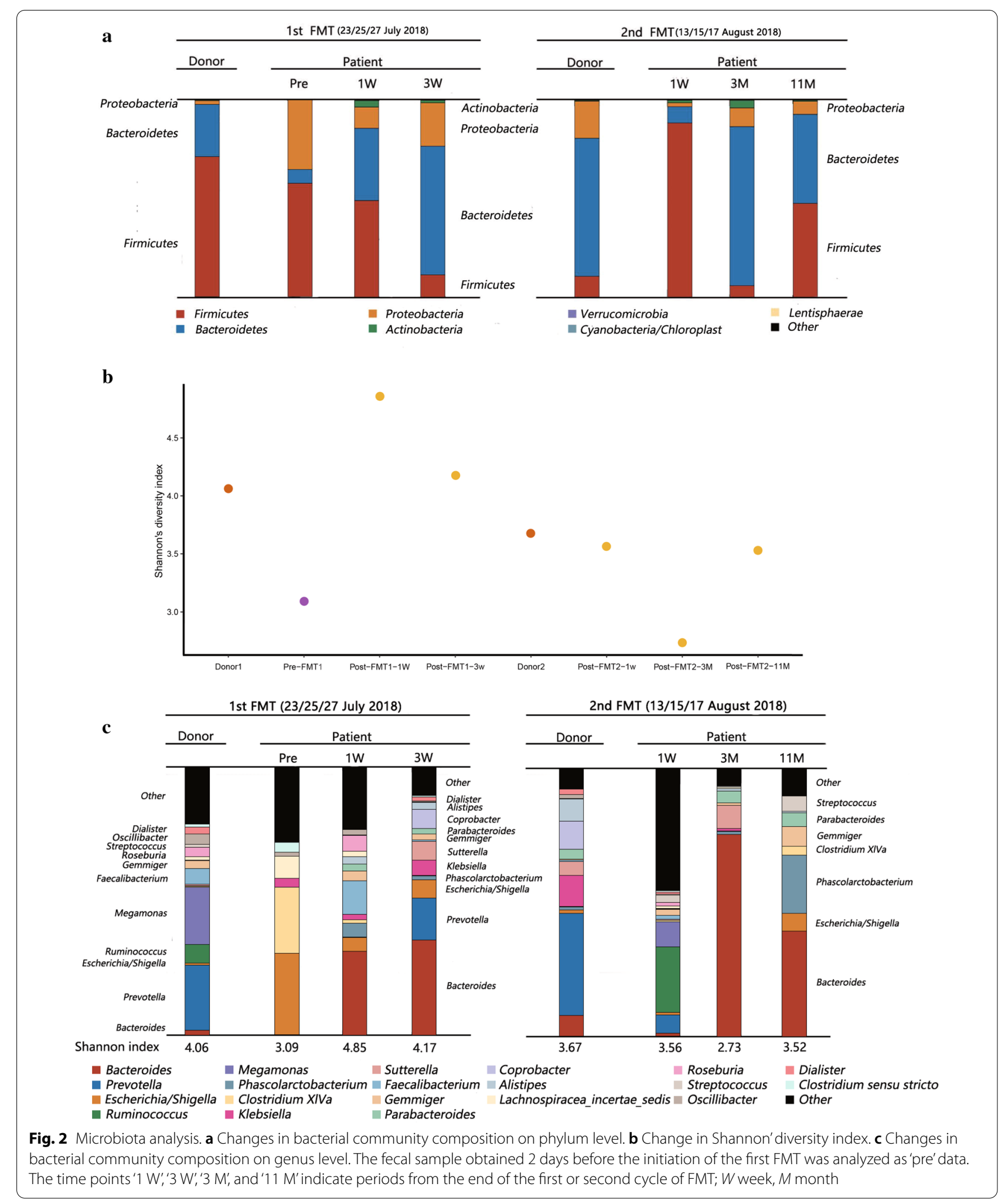




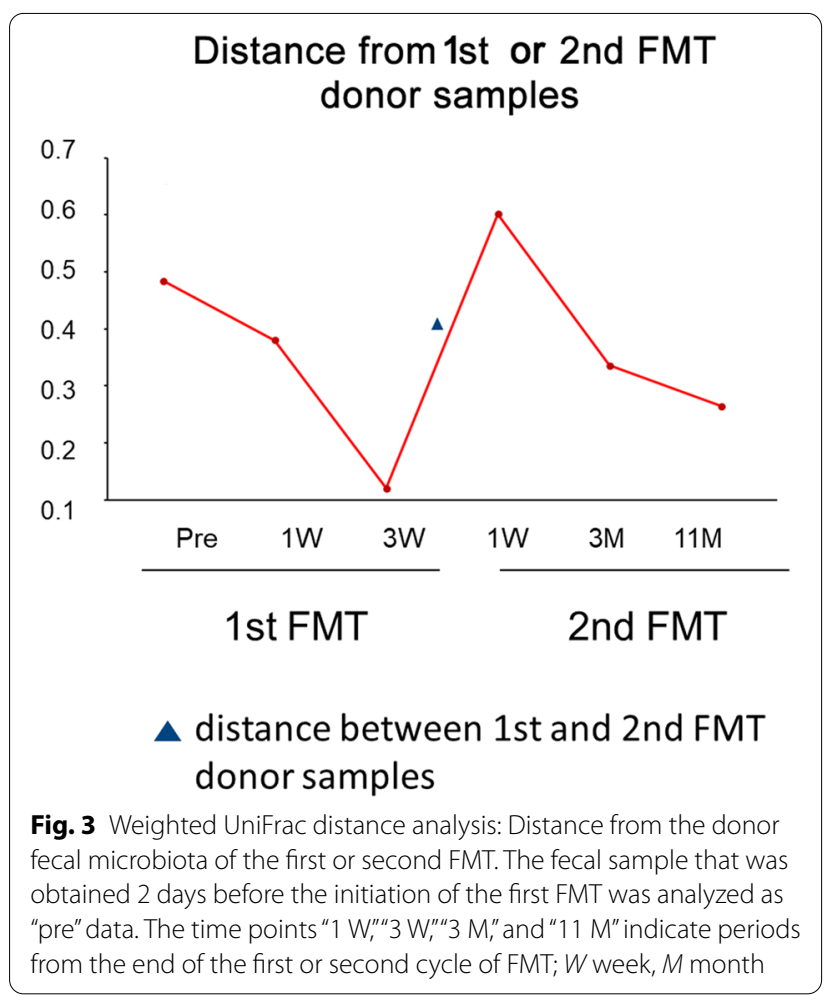

in HSCT recipients [48]. These data were significantly higher than the spontaneous decolonization group. Previous studies have also shown that antibiotic therapies are associated with dramatic increases in antibioticresistant genes, and may increase microbial resistance in the future $[49,50]$. Furthermore, due to long-term hospitalization, low functional patient status, and gut microbiota dysbiosis, even after successful decolonization, allo-HSCT recipients are more likely to reacquire colonization from other patients or the environment [51].

Several case reports and small-sample clinical studies have reported the beneficial effects of FMT towards MDRB decolonization in immunosuppressed patients with blood disorders. A prospective, single-center study by Bilinski et al. showed the complete eradication of MDRB in 15 of 20 patients with blood disorders after FMT, with a higher abundance of Barnesiella species, Bacteroides, and Butyricimonas in responders [52]. Of note, six patients received FMT after allo-HSCT. Similarly, Battipaglia et al. successfully eradicated CRE/VRE after FMT in 7 of 10 patients with hematologic malignancies, before or after allo-HCST [53]. More recently, Merli et al. showed that MDRB decolonization was achieved in four of five $(80 \%)$ pediatric patients before allo-HSCT by FMT, within 1 week [54]. These reports supported not only FMT efficacy but also demonstrated that FMT in allo-HSCT settings was safe and tolerable. Furthermore, some studies have also suggested a significant reduction in antibiotic-resistant gene carriage in recipient microbiota following FMT for CDI [55-57].

However, some studies have observed mixed conclusions. Sohn et al. performed FMT to eradicate long-term VRE colonization in three patients; however, only one patient was cleared at 15 weeks after FMT [58]. Several reasons may be responsible for these observations. First, small-sample sizes may have contributed to the different results. Second, age may be a factor affecting FMT results, as outlined in some studies $[59,60]$. The patients in the study by Sohn et al. were older (median age was 74.7 vs. 51 years in Bilinski et al. vs. 48 years in Battipaglia et al. vs. 11.4 years in Merli et al.). In a prospective comparative study, Dinh et al. observed that VRE clearance after FMT appeared to be quicker than CRE clearance $(87.5 \%$ vs. $50 \%)$ [61]. In addition to factors discussed by these authors, the age differences between the CRE and VRE groups (median age was 66 years for VRE vs. 73.5 years for CRE) may also have contributed to the different results. This may have been due to longer hospitalization and more underlying significant comorbidities in elderly patients. Other factors including stool donors, administration methods, antibiotic use before or after FMT, and the number and frequency of administrations may have impacted FMT outcomes. As a consequence, multi-center and randomized-controlled trials are ongoing to evaluate the true impact of FMT for MDRB eradication; NCT04181112 (fecal transplant for MDRO decolonization) and NCT04759001 (FMT for the decolonization of carbapenem-resistant Enterobacteriaceae).

In our case, AEs were not observed; however, FMTrelated AEs have been previously reported in other studies. Recently, a systematic review summarized the global incidence of FMT-related AEs between 2000 and 2020 [62]. Most were mild, moderate, and self-limiting, and the most frequently reported AEs were diarrhea (10\%) and abdominal discomfort/pain/cramping (7\%), which may have been due to most patients receiving FMT with impaired intestinal mucosal barriers and severe inflammation. FMT-related serious adverse events (SAEs), including infections and deaths were reported in $1.4 \%$ of patients, all of whom had mucosal barrier injuries. For MDRB decolonization in patients with hematologic malignancies, the main AEs were mild and transient gastro-intestinal symptoms, including diarrhea, abdominal discomfort, nausea, bloating, and constipation, with no major AEs reported [63]. We have summarized all recently reported FMT-related AEs in allo-HSCT patients (Table 1). In line with the literature, most AEs were mild, transient, and self-limiting, and the most frequently reported AEs were diarrhea (22.79\%) and abdominal pain/discomfort/bloating/urgency (7.35\%). 


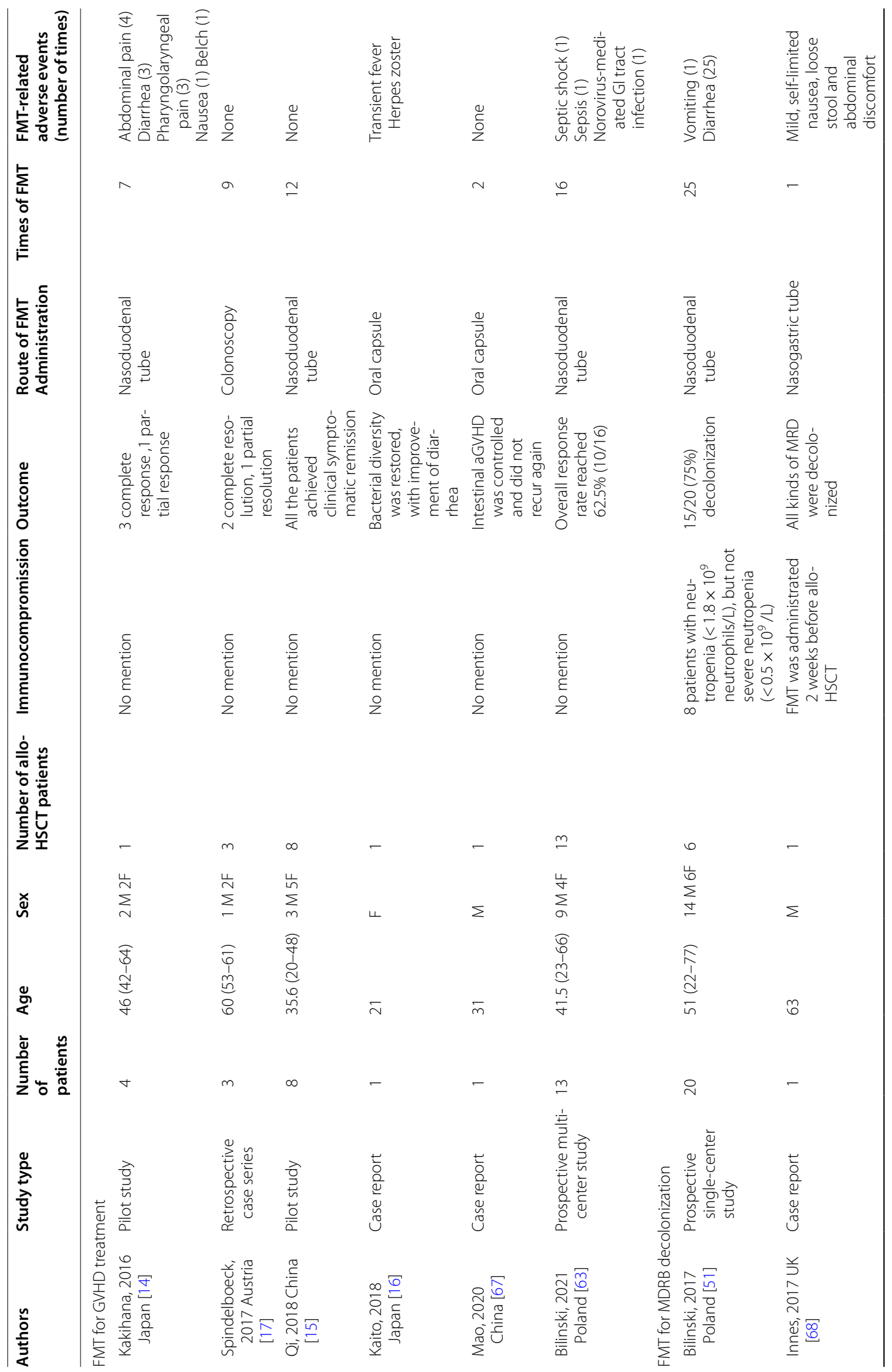




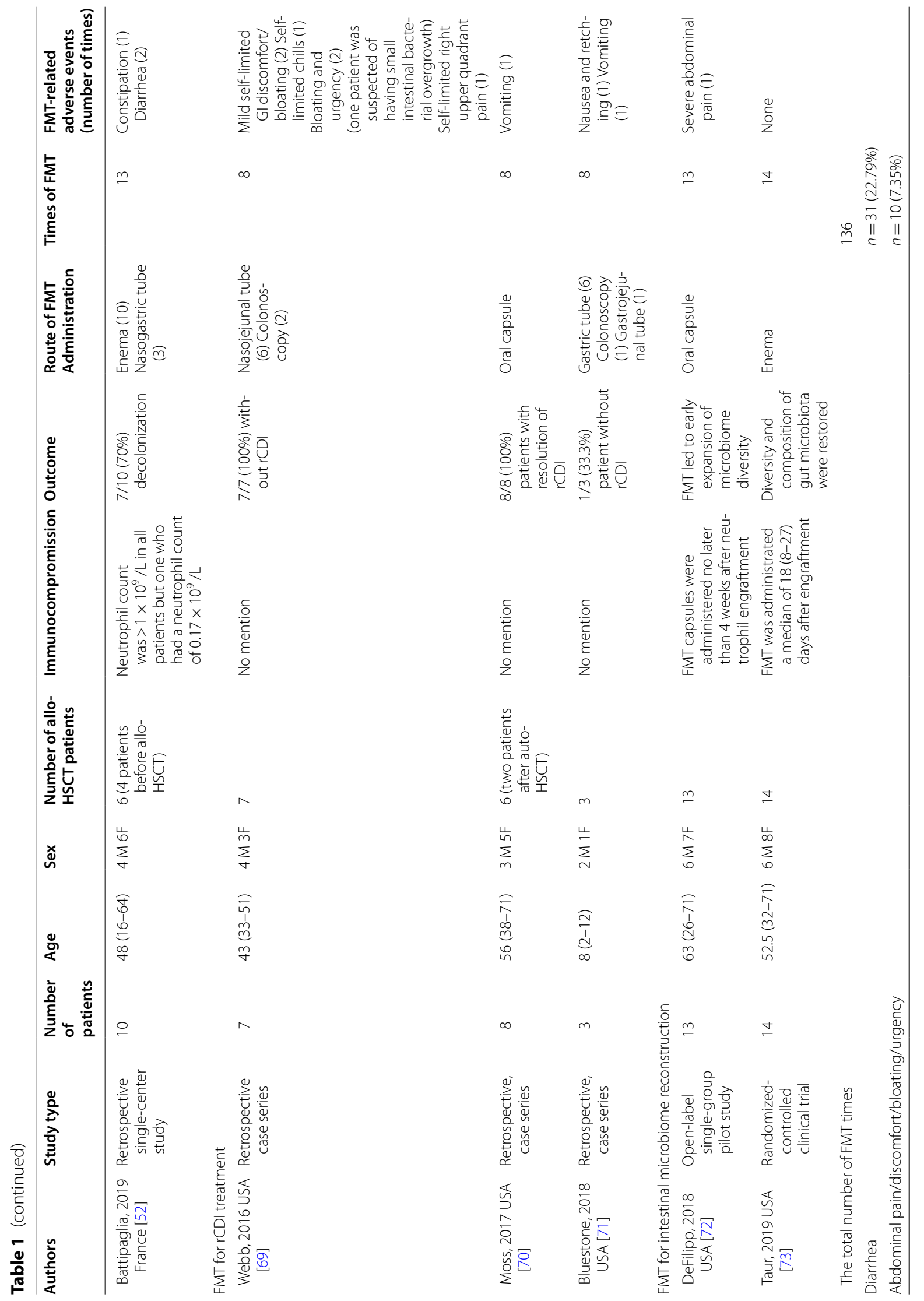




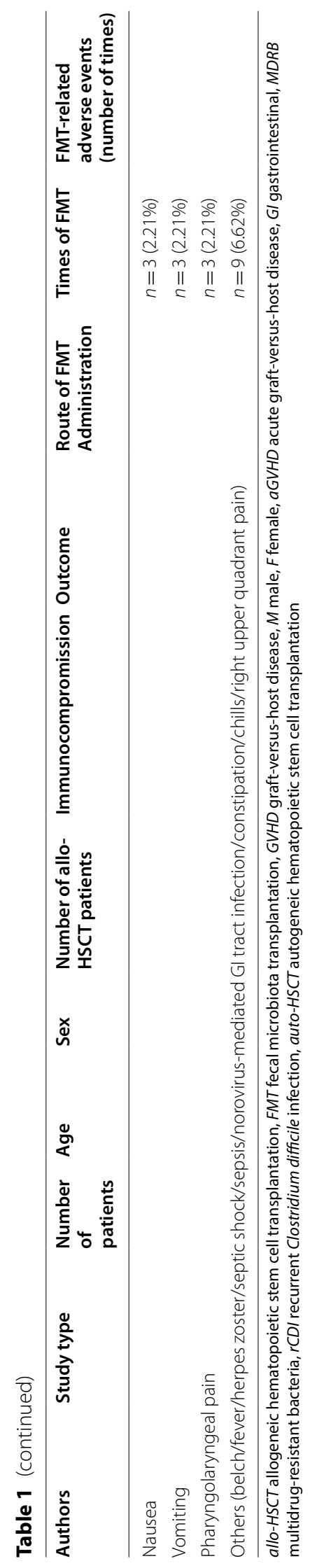


The diarrhea incidence was higher in allo-HSCT patients, especially in those with neutropenia. Other AEs including nausea, vomiting, and pharyngolaryngeal pain were reported in $2.21 \%$ of FMT procedures, respectively. Overall, the FMT has shown an excellent safety profile. However, in a most recent study by Bilinski et al., higher rate of SAEs, including septic shock, sepsis, and norovirus-mediated GI tract infection were observed, which may have been due to the poor general performance status of study patients [64]. Moreover, it was observed that a worse general performance status tended to correlate with more frequent complications. Importantly, none of these events resulted in death. In addition, several reports have indicated no significant differences in SAE rates between immunocompromised and immunocompetent patients $[65,66]$. Thus, immunosuppression may not be a contraindication for FMT; however, the procedure still should be used with caution, especially in patients with a low-performance status.

DeFilipp et al. described two immunocompromised recipients with bacteremia from drug-resistant Escherichia coli in donor stool; one recipient with hematologic malignancy who had received FMT capsules on day 3 and day 4 before allo-HSCT died [74]. This study generated an SAE safety alert due to MDRB transmission via FMT, especially in immunocompromised patients. Therefore, standardized donor-screening protocols, included MDRB detection, are urgently required in the field. To avoid potential risks from FMT, probiotic cocktails could be used as alternative strategies. Nagpal et al. developed a novel human-origin probiotic cocktail containing five Lactobacillus and five Enterococcus strains from healthy infant gut which modulated the fecal microbiome and enhanced SCFAs in mouse gut and human feces [75]. Similarly, Ahmadi et al., in an aged mouse model, showed the probiotic cocktail counteracted metabolic syndrome, and deeply reshaped the gut microbiota [76]. However, according to our literature review, this novel strategy has not been used to decolonize MDRB, and therefore, further study is warranted.

In our case, tandem FMT cycles resulted in successful CRE decolonization of the gut, and a concomitant improvement in quality of life. As we observed only one patient, limited conclusions may be drawn; however, these data suggest that multiple FMTs may be viable options for CRE decolonization. Additionally, our 26-month follow-up was longer than all previous studies. Many aspects of FMT remain unknown and the longterm consequences are unclear, and therefore, standardized and harmonized studies are required to properly evaluate FMT as a promising clinical strategy for microbiome-related disorders.

\section{Abbreviations}

CRE: Carbapenem-resistant Enterobacteriaceae; HSCT: Hematopoietic stem cell transplantation; allo-HSCT: Allogeneic hematopoietic stem cell transplantation; FMT: Fecal microbiota transplantation;; CDI: Clostridium difficile infection; GVHD: Graft-versus-host disease; MDRB: Multidrug-resistant bacteria; AML: Acute myeloid leukemia; MRD: Minimal residual disease; CRKp: Carbapenem-resistant Klebsiella pneumonia; CT: Computerized tomography; GMP: Good manufacturing practice; AEs: Adverse events; SCFAs: Short-chain fatty acids; VRE: Vancomycin-resistant enterococci; SAEs: Serious adverse events; M: Male; F: Female; aGVHD: Acute graft-versus-host disease; Gl: Gastrointestinal; rCDI: Recurrent Clostridium difficile infection; auto-HSCT: Autogeneic hematopoietic stem cell transplantation.

\section{Supplementary Information}

The online version contains supplementary material available at https://doi. org/10.1186/s40001-021-00508-8.

Additional file 1: Figure S1. Antibiogram of the cultured CRKp. $R$ resistant, $\mathrm{S}$ sensitive.

Additional file 2: Table S1. Protocol of donor screening in MedBiome. IBD inflammatory bowel disease, IBS irritable bowel syndrome, GI gastrointestinal, CRP C- reactive protein, ESR erythrocyte sedimentation rate, HIV human immunodeficiency virus.

\section{Acknowledgements}

We thank the patient and the donor for provision of clinical data.

\section{Authors' contributions}

YT perform the fecal microbiota transplantation and supervised the analyses and manuscript preparation. FS collected and analyzed the data, and wrote the manuscript. All authors discussed and interpreted the results. All authors read and approved the final manuscript.

\section{Funding}

This work was funded in part by the National Natural Science Foundation of China (81670169) and Medical Science and Technology Project of Zhejiang Province (2010KYA075).

\section{Availability of data and materials}

The datasets used and/or analyzed during the current study are available from the corresponding author on reasonable request.

\section{Declarations}

\section{Ethics approval}

The study protocol was approved by the Clinical Research Ethics Committee of the First Affiliated Hospital of Zhejiang University School of Medicine and passed the Chinese Clinical Trial Registration Certification (ChiCTR1800016182, this patient has both CRE colonization and GVHD). Written informed consent was obtained from both the donor and the patient according to the policies of the committee.

\section{Consent to participate}

Informed consent was obtained from the patient and the donor.

\section{Consent for publication}

Consent for publication was obtained from all participants to the study. Data were published anonymously.

\section{Competing interests}

The authors declare that they have no competing interests.

\section{Author details}

'Bone Marrow Transplantation Center, The First Affiliated Hospital, Zhejiang University School of Medicine, 79 Qingchun Road, Hangzhou 310003, China. ${ }^{2}$ Institute of Hematology, Zhejiang University, Hangzhou, Zhejiang, People's Republic of China. ${ }^{3}$ Hematology Department, The Cancer Hospital 
of the University of Chinese Academy of Sciences (Zhejiang Cancer Hospital), Institute of Basic Medicine and Cancer (IBMC), Chinese Academy of Sciences, 1 Banshan East Road, Hangzhou 310022, Zhejiang, China.

\section{Received: 16 December 2020 Accepted: 13 April 2021} Published online: 28 April 2021

\section{References}

1. Girmenia C, Rossolini GM, Piciocchi A, Bertaina A, Pisapia G, Pastore D, et al. Infections by carbapenem-resistant Klebsiella pneumoniae in SCT recipients: a nationwide retrospective survey from Italy. Bone Marrow Transplant. 2015;50(2):282-8.

2. Zhang L, Zhai W, Lin Q, Zhu X, Xiao Z, Yang R, et al. Carbapenem-resistant Enterobacteriaceae in hematological patients: outcome of patients with carbapenem-resistant Enterobacteriaceae infection and risk factors for progression to infection after rectal colonization. Int J Antimicrob Agents. 2019;54(4):527-59.

3. Bilinski J, Robak K, Peric Z, Marchel H, Karakulska-Prystupiuk E, Halaburda $K$, et al. Impact of gut colonization by antibiotic-resistant bacteria on the outcomes of allogeneic hematopoietic stem cell transplantation: a retrospective, single-center study. Biol Blood Marrow Transplant. 2016:22(6):1087-93.

4. Trecarichi EM, Pagano L, Martino B, Candoni A, Di Blasi R, Nadali G, et al. Bloodstream infections caused by Klebsiella pneumoniae in onco-hematological patients: clinical impact of carbapenem resistance in a multicentre prospective survey. Am J Hematol. 2016;91(11):1076-81.

5. Pagano L, Caira M, Trecarichi EM, Spanu T, Di Blasi R, Sica S, et al. Carbapenemase-producing Klebsiella pneumoniae and hematologic malignancies. Emerg Infect Dis. 2014;20(7):1235-6.

6. van Nood E, Vrieze A, Nieuwdorp M, Fuentes S, Zoetendal EG, de Vos WM, et al. Duodenal infusion of donor feces for recurrent Clostridium difficile. N Engl J Med. 2013;368(5):407-15.

7. McDonald LC, Gerding DN, Johnson S, Bakken JS, Carroll KC, Coffin SE, et al. Clinical practice guidelines for Clostridium difficile infection in adults and children: 2017 update by the Infectious Diseases Society of America (IDSA) and Society for Healthcare Epidemiology of America (SHEA). Clin Infect Dis. 2018;66(7):e1-48.

8. Cammarota G, laniro G, Tilg H, Rajilić-Stojanović M, Kump P, Satokari R, et al. European consensus conference on faecal microbiota transplantation in clinical practice. Gut. 2017;66(4):569-80.

9. Haifer C, Kelly CR, Paramsothy S, Andresen D, Papanicolas LE, McKew GL, et al. Australian consensus statements for the regulation, production and use of faecal microbiota transplantation in clinical practice. Gut. 2020:69(5):801-10.

10. Costello SP, Hughes PA, Waters $O$, Bryant RV, Vincent AD, Blatchford P, et al. Effect of fecal microbiota transplantation on 8-week remission in patients with ulcerative colitis: a randomized clinical trial. JAMA 2019;321(2):156-64.

11. Paramsothy S, Kamm MA, Kaakoush NO, Walsh AJ, van den Bogaerde J, Samuel D, et al. Multidonor intensive faecal microbiota transplantation for active ulcerative colitis: a randomised placebo-controlled trial. Lancet. 2017;389(10075):1218-28.

12. Johnsen PH, Hilpüsch F, Cavanagh JP, Leikanger IS, Kolstad C, Valle PC, et al. Faecal microbiota transplantation versus placebo for moderate-tosevere irritable bowel syndrome: a double-blind, randomised, placebocontrolled, parallel-group, single-centre trial. Lancet Gastroenterol Hepatol. 2018;3(1):17-24.

13. El-Salhy M, Hatlebakk JG, Gilja OH, Kristoffersen AB, Hausken T. Efficacy of faecal microbiota transplantation for patients with irritable bowel syndrome in a randomised, double-blind, placebo-controlled study. Gut. 2020;69(5):859-67.

14. Kakihana K, Fujioka Y, Suda W, Najima Y, Kuwata G, Sasajima S, et al. Fecal microbiota transplantation for patients with steroid-resistant acute graftversus-host disease of the gut. Blood. 2016;128(16):2083-8.

15. Qi X, Li X, Zhao Y, Wu X, Chen F, Ma X, et al. Treating steroid refractory intestinal acute graft-vs.-host disease with fecal microbiota transplantation: a pilot study. Front Immunol. 2018;9:2195.

16. Kaito S, Toya T, Yoshifuji K, Kurosawa S, Inamoto K, Takeshita K, et al. Fecal microbiota transplantation with frozen capsules for a patient with refractory acute gut graft-versus-host disease. Blood Adv. 2018;2(22):3097-101.

17. Spindelboeck W, Schulz E, Uhl B, Kashofer K, Aigelsreiter A, ZinkeCerwenka W, et al. Repeated fecal microbiota transplantations attenuate diarrhea and lead to sustained changes in the fecal microbiota in acute, refractory gastrointestinal graft-versus-host-disease. Haematologica. 2017;102(5):e210-3.

18. Davido B, Batista R, Michelon H, Lepainteur M, Bouchand F, Lepeule R, et al. Is faecal microbiota transplantation an option to eradicate highly drug-resistant enteric bacteria carriage? J Hosp Infect. 2017;95(4):433-7.

19. Saïdani N, Lagier JC, Cassir N, Million M, Baron S, Dubourg G, et al. Faecal microbiota transplantation shortens the colonisation period and allows re-entry of patients carrying carbapenamase-producing bacteria into medical care facilities. Int J Antimicrob Agents. 2019;53(4):355-61.

20. Crum-Cianflone NF, Sullivan E, Ballon-Landa G. Fecal microbiota transplantation and successful resolution of multidrug-resistant-organism colonization. J Clin Microbiol. 2015;53(6):1986-9.

21. Manges AR, Steiner TS, Wright AJ. Fecal microbiota transplantation for the intestinal decolonization of extensively antimicrobial-resistant opportunistic pathogens: a review. Infect Dis. 2016;48(8):587-92.

22. Allegretti JR, Mullish BH, Kelly C, Fischer M. The evolution of the use of faecal microbiota transplantation and emerging therapeutic indications. Lancet. 2019;394(10196):420-31.

23. Fischer M, Sipe B, Cheng YW, Phelps E, Rogers N, Sagi S, et al. Fecal microbiota transplant in severe and severe-complicated Clostridium difficile: a promising treatment approach. Gut Microbes. 2017;8(3):289-302.

24. Ianiro G, Masucci L, Quaranta G, Simonelli C, Lopetuso LR, Sanguinetti $M$, et al. Randomised clinical trial: faecal microbiota transplantation by colonoscopy plus vancomycin for the treatment of severe refractory Clostridium difficile infection-single versus multiple infusions. Aliment Pharmacol Ther. 2018:48(2):152-9.

25. Tamburini FB, Andermann TM, Tkachenko E, Senchyna F, Banaei N, Bhatt AS. Precision identification of diverse bloodstream pathogens in the gut microbiome. Nat Med. 2018;24(12):1809-14.

26. Samet A, Sledzińska A, Krawczyk B, Hellmann A, Nowicki S, Kur J, et al. Leukemia and risk of recurrent Escherichia coli bacteremia: genotyping implicates E. coli translocation from the colon to the bloodstream. Eur J Clin Microbiol Infect Dis. 2013;32(11):1393-400.

27. Cui B, Li P, Xu L, Zhao Y, Wang H, Peng Z, et al. Step-up fecal microbiota transplantation strategy: a pilot study for steroid-dependent ulcerative colitis. J Transl Med. 2015;12(13):298.

28. Zhang T, Lu G, Zhao Z, Liu Y, Shen Q, Li P, et al. Washed microbiota transplantation vs. manual fecal microbiota transplantation: clinical findings, animal studies and in vitro screening. Protein Cell. 2020;11(4):251-66.

29. Costello EK, Lauber CL, Hamady M, Fierer N, Gordon Jl, Knight R. Bacterial community variation in human body habitats across space and time. Science. 2009;326(5960):1694-7.

30. Rinninella E, Raoul P, Cintoni M, Franceschi F, Miggiano GAD, Gasbarrini A, et al. What is the healthy gut microbiota composition? A changing ecosystem across age, environment, diet, and Diseases. Microorganisms. 2019;7(1):14.

31. Ubeda C, Taur Y, Jenq RR, Equinda MJ, Son T, Samstein M, et al. Vancomycin-resistant Enterococcus domination of intestinal microbiota is enabled by antibiotic treatment in mice and precedes bloodstream invasion in humans. J Clin Invest. 2010;120(12):4332-41.

32. Biagi E, Zama D, Nastasi C, Consolandi C, Fiori J, Rampelli S, et al. Gut microbiota trajectory in pediatric patients undergoing hematopoietic SCT. Bone Marrow Transplant. 2015;50(7):992-8.

33. Doki N, Suyama M, Sasajima S, Ota J, Igarashi A, Mimura I, et al. Clinical impact of pre-transplant gut microbial diversity on outcomes of allogeneic hematopoietic stem cell transplantation. Ann Hematol. 2017;96(9):1517-23.

34. Lee YJ, Arguello ES, Jenq RR, Littmann E, Kim GJ, Miller LC, et al. Protective factors in the intestinal microbiome against Clostridium difficile infection in recipients of allogeneic hematopoietic stem cell transplantation. J Infect Dis. 2017;215(7):1117-23.

35. Stoma I, Littmann ER, Peled JU, Giralt S, van den Brink MRM, Pamer EG, et al. Compositional flux within the intestinal microbiota and risk for bloodstream infection with gram-negative bacteria. Clin Infect Dis. 2020. https://doi.org/10.1093/cid/ciaa068. 
36. Staffas $A$, da Silva MB, van den Brink MR. The intestinal microbiota in allogeneic hematopoietic cell transplant and graft-versus-host disease. Blood. 2017;129(8):927-33.

37. Lee JJ, Yong D, Suk KT, Kim DJ, Woo HJ, Lee SS, et al. Alteration of gut microbiota in carbapenem-resistant Enterobacteriaceae carriers during fecal microbiota transplantation according to decolonization periods. Microorganisms. 2021;9(2):352.

38. Taur Y, Jenq RR, Perales MA, Littmann ER, Morjaria S, Ling L, et al. The effects of intestinal tract bacterial diversity on mortality following allogeneic hematopoietic stem cell transplantation. Blood 2014;124(7):1174-82.

39. Pickard JM, Zeng MY, Caruso R, Núñez G. Gut microbiota: role in pathogen colonization, immune responses, and inflammatory disease. Immunol Rev. 2017;279(1):70-89.

40. Shono Y, van den Brink MRM. Gut microbiota injury in allogeneic haematopoietic stem cell transplantation. Nat Rev Cancer. 2018;18(5):283-95.

41. Kim S, Covington A, Pamer EG. The intestinal microbiota: antibiotics, colonization resistance, and enteric pathogens. Immunol Rev. 2017;279(1):90-105.

42. Davido B, Moussiegt A, Dinh A, Bouchand F, Matt M, Senard O, et al. Germs of thrones-spontaneous decolonization of carbapenemResistant Enterobacteriaceae (CRE) and vancomycin-resistant Enterococci (VRE) in western Europe: is this myth or reality? Antimicrob Resist Infect Control. 2018;13(7):100

43. Haverkate MR, Weiner S, Lolans K, Moore NM, Weinstein RA, Bonten MJ, et al. Duration of colonization with Klebsiella pneumoniae carbapenemase-producing bacteria at long-term acute care hospitals in Chicago, Illinois. Open Forum Infect Dis. 2016;3(4):ofw178.

44. Bar-Yoseph H, Hussein K, Braun E, Paul M. Natural history and decolonization strategies for ESBL/carbapenem-resistant Enterobacteriaceae carriage: systematic review and meta-analysis. J Antimicrob Chemother. 2016;71(10):2729-39.

45. Saidel-Odes L, Polachek H, Peled N, Riesenberg K, Schlaeffer F, Trabelsi Y, et al. A randomized, double-blind, placebo-controlled trial of selective digestive decontamination using oral gentamicin and oral polymyxin $\mathrm{E}$ for eradication of carbapenem-resistant Klebsiella pneumoniae carriage. Infect Control Hosp Epidemiol. 2012;33(1):14-9.

46. Lambelet $P$, Tascini C, Fortunato S, Stefanelli A, Simonetti F, Vettori C, et al. Oral gentamicin therapy for carbapenem-resistant Klebsiella pneumoniae gut colonization in hematologic patients: a single center experience. New Microbiol. 2017;40(3):161-4.

47. Oren I, Sprecher H, Finkelstein R, Hadad S, Neuberger A, Hussein K, et al. Eradication of carbapenem-resistant Enterobacteriaceae gastrointestinal colonization with nonabsorbable oral antibiotic treatment: a prospective controlled trial. Am J Infect Control. 2013;41(12):1167-72.

48. Zuckerman $T$, Benyamini N, Sprecher H, Fineman R, Finkelstein R, Rowe $\mathrm{JM}$, et al. SCT in patients with carbapenem resistant Klebsiella pneumoniae: a single center experience with oral gentamicin for the eradication of carrier state. Bone Marrow Transplant. 2011;46(9):1226-30.

49. Oostdijk EA, de Smet AM, Blok HE, Thieme Groen ES, van Asselt GJ, Benus $R F$, et al. Ecological effects of selective decontamination on resistant gram-negative bacterial colonization. Am J Respir Crit Care Med. 2010;181(5):452-7.

50. Halaby T, Al Naiemi N, Kluytmans J, van der Palen J, VandenbrouckeGrauls CM. Emergence of colistin resistance in Enterobacteriaceae after the introduction of selective digestive tract decontamination in an intensive care unit. Antimicrob Agents Chemother. 2013;57(7):3224-9.

51. Feldman N, Adler A, Molshatzki N, Navon-Venezia S, Khabra E, Cohen D, et al. Gastrointestinal colonization by KPC-producing Klebsiella pneumoniae following hospital discharge: duration of carriage and risk factors for persistent carriage. Clin Microbiol Infect. 2013;19(4):E190-6.

52. Bilinski J, Grzesiowski P, Sorensen N, Madry K, Muszynski J, Robak K, et al. Fecal microbiota transplantation in patients with blood disorders inhibits gut colonization with antibiotic-resistant bacteria: results of a prospective, single-center study. Clin Infect Dis. 2017;65(3):364-70.

53. Battipaglia G, Malard F, Rubio MT, Ruggeri A, Mamez AC, Brissot E, et al. Fecal microbiota transplantation before or after allogeneic hematopoietic transplantation in patients with hematologic malignancies carrying multidrug-resistance bacteria. Haematologica. 2019;104(8):1682-8.

54. Merli P, Putignani L, Ruggeri A, Del Chierico F, Gargiullo L, Galaverna F, et al. Decolonization of multi-drug resistant bacteria by fecal microbiota transplantation in five pediatric patients before allogeneic hematopoietic stem cell transplantation: gut microbiota profiling, infectious and clinical outcomes. Haematologica. 2020;105(11):2686-90.

55. Millan B, Park H, Hotte N, Mathieu O, Burguiere P, Tompkins TA, et al. Fecal microbial transplants reduce antibiotic-resistant genes in patients with recurrent Clostridium difficile infection. Clin Infect Dis. 2016;62(12):1479-86.

56. Hourigan SK, Ahn M, Gibson KM, Pérez-Losada M, Felix G, Weidner M, et al. Fecal transplant in children with Clostridioides difficile gives sustained reduction in antimicrobial resistance and potential pathogen burden. Open Forum Infect Dis. 2019;6(10):ofz379.

57. Langdon A, Schwartz DJ, Bulow C, Sun X, Hink T, Reske KA, et al. Microbiota restoration reduces antibiotic-resistant bacteria gut colonization in patients with recurrent Clostridioides difficile infection from the open-label PUNCH CD study. Genome Med. 2021;13(1):28.

58. Sohn KM, Cheon S, Kim YS. Can fecal microbiota transplantation (fmt) eradicate fecal colonization with vancomycin-resistant Enterococci (VRE)? Infect Control Hosp Epidemiol. 2016;37(12):1519-21.

59. Li YT, Cai HF, Wang ZH, Xu J, Fang JY. Systematic review with metaanalysis: long-term outcomes of faecal microbiota transplantation for Clostridium difficile infection. Aliment Pharmacol Ther. 2016;43(4):445-57.

60. Lee CH, Belanger JE, Kassam Z, Smieja M, Higgins D, Broukhanski G, et al. The outcome and long-term follow-up of 94 patients with recurrent and refractory Clostridium difficile infection using single to multiple fecal microbiota transplantation via retention enema. Eur J Clin Microbiol Infect Dis. 2014;33(8):1425-8.

61. Dinh A, Fessi H, Duran C, Batista R, Michelon H, Bouchand F, et al. Clearance of carbapenem-resistant Enterobacteriaceae vs vancomycin-resistant Enterococci carriage after faecal microbiota transplant: a prospective comparative study. J Hosp Infect. 2018;99(4):481-6.

62. Marcella C, Cui B, Kelly CR, laniro G, Cammarota G, Zhang F. Systematic review: the global incidence of faecal microbiota transplantationrelated adverse events from 2000 to 2020. Aliment Pharmacol Ther. 2021;53(1):33-42

63. Alagna L, Palomba E, Mangioni D, Bozzi G, Lombardi A, Ungaro R, et al. Multidrug-resistant gram-negative bacteria decolonization in immunocompromised patients: a focus on fecal microbiota transplantation. Int J Mol Sci. 2020;21(16):5619.

64. Bilinski J, Lis K, Tomaszewska A, Grzesiowski P, Dzieciatkowski T, Tyszka $M$, et al. Fecal microbiota transplantation in patients with acute and chronic graft-versus-host disease-spectrum of responses and safety profile. Results from a prospective, multicenter study. Am J Hematol. 2021;96(3):E88-91.

65. Mandalia A, Ward A, Tauxe W, Kraft CS, Dhere T. Fecal transplant is as effective and safe in immunocompromised as non-immunocompromised patients for Clostridium difficile. Int J Colorectal Dis. 2016:31(5):1059-60.

66. Shogbesan O, Poudel DR, Victor S, Jehangir A, Fadahunsi O, Shogbesan $\mathrm{G}$, et al. A systematic review of the efficacy and safety of fecal microbiota transplant for Clostridium difficile infection in immunocompromised patients. Can J Gastroenterol Hepatol. 2018;2(2018):1394379.

67. Mao D, Jiang Q, Sun Y, Mao Y, Guo L, Zhang Y, et al. Treatment of intestinal graft-versus-host disease with unrelated donor fecal microbiota transplantation capsules: a case report. Medicine. 2020;99(38):e22129.

68. Innes AJ, Mullish BH, Fernando F, Adams G, Marchesi JR, Apperley JF, et al. Faecal microbiota transplant: a novel biological approach to extensively drug-resistant organism-related non-relapse mortality. Bone Marrow Transplant. 2017:52(10):1452-4.

69. Webb BJ, Brunner A, Ford CD, Gazdik MA, Petersen FB, Hoda D. Fecal microbiota transplantation for recurrent Clostridium difficile infection in hematopoietic stem cell transplant recipients. Transpl Infect Dis. 2016;18(4):628-33.

70. Moss EL, Falconer SB, Tkachenko E, Wang M, Systrom H, Mahabamunuge J, et al. Long-term taxonomic and functional divergence from donor bacterial strains following fecal microbiota transplantation in immunocompromised patients. PLOS ONE. 2017;12(8):e0182585.

71. Bluestone H, Kronman MP, Suskind DL. Fecal microbiota transplantation for recurrent Clostridium difficile Infections in pediatric hematopoietic stem cell transplant recipients. J Pediatric Infect Dis Soc. 2018;7(1):e6-8.

72. DeFilipp Z, Peled JU, Li S, Mahabamunuge J, Dagher Z, Slingerland AE, et al. Third-party fecal microbiota transplantation following allo-HCT reconstitutes microbiome diversity. Blood Adv. 2018;2(7):745-53. 
73. Taur Y, Coyte K, Schluter J, Robilotti E, Figueroa C, Gjonbalaj M, et al. Reconstitution of the gut microbiota of antibiotic-treated patients by autologous fecal microbiota transplant. Sci Transl Med. 2018;10(460):eaap9489.

74. DeFilipp Z, Bloom PP, Soto MT, Mansour MK, Sater MRA, Huntley MH, et al. Drug-resistant E. coli bacteremia transmitted by fecal microbiota transplant. N Engl J Med. 2019;381(21):2043-50.

75. Nagpal R, Wang S, Ahmadi S, Hayes J, Gagliano J, Subashchandrabose $S$, et al. Human-origin probiotic cocktail increases short-chain fatty acid production via modulation of mice and human gut microbiome. Sci Rep. 2018:8(1):12649.
76. Ahmadi S, Wang S, Nagpal R, Wang B, Jain S, Razazan A, et al. A humanorigin probiotic cocktail ameliorates aging-related leaky gut and inflammation via modulating the microbiota/taurine/tight junction axis. JCl Insight. 2020;5(9):e132055.

\section{Publisher's Note}

Springer Nature remains neutral with regard to jurisdictional claims in published maps and institutional affiliations.
Ready to submit your research? Choose BMC and benefit from:

- fast, convenient online submission

- thorough peer review by experienced researchers in your field

- rapid publication on acceptance

- support for research data, including large and complex data types

- gold Open Access which fosters wider collaboration and increased citations

- maximum visibility for your research: over $100 \mathrm{M}$ website views per year

At BMC, research is always in progress.

Learn more biomedcentral.com/submissions 